Research Paper

\title{
Association of preoperative systemic Immune-inflammation Index and Prognostic Nutritional Index with survival in patients with Upper Tract Urothelial Carcinoma
}

\author{
Yangqin Zheng ${ }^{1^{*}}$, Dongdong $\mathrm{Yu}^{2^{*}}$, Zhixian $\mathrm{Yu}^{3^{*}}$, Dewei Zhao ${ }^{4}$, Yuming Chen ${ }^{5^{*}}$, Wu Chen ${ }^{6}$, Yeping Li ${ }^{3 凶}$, \\ Binwei $\operatorname{Lin}^{7 凶}$ and Xiaomin $\mathrm{Gao}^{8 凶}$ \\ 1. Department of Hematology, The Third Clinical Institute Affiliated to Wenzhou Medical University, People's Hospital of Wenzhou, Wenzhou, Zhejiang \\ province, 325006, P.R. China. \\ 2. Department of Andrology, The First Affiliated Hospital of Wenzhou Medical University, Wenzhou, Zhejiang province, 325006, P.R. China. \\ 3. Department of Urology, The First Affiliated Hospital of Wenzhou Medical University, Wenzhou, Zhejiang province,325006, P.R. China. \\ 4. Department of Urology, Wenzhou Central Hospital, Wenzhou, Zhejiang province, 325200, P.R. China. \\ 5. Department of Urology, Affiliated Hospital of Yangzhou University, Yangzhou, Jiangsu province, 225001, P.R. China \\ 6. Department of Urology, The Third Clinical Institute Affiliated to Wenzhou Medical University, People's Hospital of Wenzhou, Wenzhou, Zhejiang \\ province, 325006, P.R. China. \\ 7. Department of Urology, Rui'an People's Hospital, The Third Affiliated Hospital of the Wenzhou Medical University, Wenzhou, Zhejiang province, 325200, \\ P.R. China. \\ 8. Department of Urology, Changhai Hospital, Second Military Medical University, Shanghai, 200433, P.R. China. \\ *These authors equally contributed to this manuscript.
}

$\triangle$ Corresponding authors: Dr Xiaomin Gao, Department of Urology, Changhai Hospital, Second Military Medical University, 168 Changhai Road, Yangpu District, Shanghai 200433, P.R. China; Dr Binwei Lin, Department of Urology, Rui' an People's Hospital, The Third Affiliated Hospital of the Wenzhou Medical University, Wenzhou, Zhejiang, 325200, P.R. China; Dr Yeping Li, Department of Urology, The First Affiliated Hospital of Wenzhou Medical University, Wenzhou, Zhejiang province, 325006, P.R. China, E-mail: doctorgaoxiaomin@163.com (X.G); 359039363@qq.com (B.L); seasky13@126.com (Y.L).

(c) The author(s). This is an open access article distributed under the terms of the Creative Commons Attribution License (https://creativecommons.org/licenses/by/4.0/). See http:/ /ivyspring.com/terms for full terms and conditions.

Received: 2020.02.14; Accepted: 2020.07.13; Published: 2020.07.25

\begin{abstract}
Background: Both systemic inflammation response and malnutrition are closely related to poor prognosis in patients with certain types of solid tumor. This study investigated the prognostic value of the preoperative combination of systemic immune-inflammation index and prognostic nutritional index (SII-PNI) in patients with upper tract urothelial carcinoma (UTUC) undergoing radical nephroureterectomy (RNU).

Methods: The predictive ability of SII-PNI was developed and further validated in a cohort of 525 UTUC patients (253 in the training cohort and 272 in the validation cohort) who received RNU.

Results: Survival analysis indicated that a SII $\geq 672.44$ was significantly associated with worse overall survival (OS), cancer-specific survival (CSS), and recurrence-free survival (RFS) while a PNI $\geq 47.83$ was associated with better survival outcomes (All $P$-values $<0.05$ ). The combination of simultaneously SIl $\geq 672.44$ and $\mathrm{PNI}<47.83$ was a powerful independent risk factor for OS, CSS, and RFS $(P<0.05)$. The SII-PNI had the largest area under the curve (AUC) compared to that for SII or PNI alone and other clinical factors, indicating its superior for predicting survival. In addition, the incorporation of the SII-PNI into established nomograms or current clinical parameters such as pathologic $T$ stage and $\mathrm{N}$ stage, achieved higher c-indexes or larger AUC than without, indicating that adding SII-PNI helped predict prognosis. All results were found in the training cohort and confirmed in the validation cohort.

Conclusions: SII-PNI was a strong independent predictor of UTUC patients after RNU.
\end{abstract}

Key words: upper tract urothelial carcinoma; systemic immune-inflammation index; prognostic nutritional index; prognosis 


\section{Introduction}

Despite its status as a relatively uncommon disease, the postoperative survival outcome of upper tract urothelial carcinoma (UTUC) remains unsatisfactory even after radical nephroureterectomy (RNU) with bladder cuff excision. UTUC is remarkably aggressive that a large number of patients will inevitably experience tumor recurrence, metastasis, or even death after surgery $[1,2]$. The five-year cancer-specific survival (CSS) of UTUC patients ranges from $50-80 \%$ following surgery $[3,4]$. Many preoperative and postoperative factors have been identified as risk predictors of UTUC for patient ${ }^{\prime}$ risk stratification in order to provide optimal and timely treatment strategies. Traditional risk biomarkers, including pathologic T stage, lymph node status, distant metastasis, tumor size and grade, and patient age, are commonly adopted to assess the prognosis of UTUC in clinical decision-making, although urological outcomes have not significantly improved in the last three decades [5]. Therefore, more accurate predictors of survival outcomes after RNU are required.

An increasing number of studies have evaluated the impact of inflammatory and immune variables, including neutrophil-to-lymphocyte ratio (NLR), platelet-to-lymphocyte ratio (PLR), and monocyte-tolymphocyte ratio (MLR), on the prognosis of UTUC [6-8]. However, these inflammation-based biomarkers were too simple, consisting of only two circulating immune cells. Furthermore, the potential role of NLR in patients with UTUC remains controversial [7]. Recently, the systemic immune-inflammation index (SII), based on the counts of neutrophils, platelets, and lymphocytes, was developed and had been identified as a powerful and accurate predictor in several solid tumors, including osteosarcoma, esophageal squamous cell carcinoma, lung cancer, and UTUC [6, 9-11]. Preoperative malnutritional status is also closely related to postoperative survival outcomes in cancer patients [12]. Recently, several studies reported the potential role of novel indicators based on inflammatory and nutritional variables in patients with cancer [13-15]. The prognostic nutritional index (PNI), which is calculated from serum albumin level and lymphocyte counts, is one parameters that reflects preoperative nutritional status and has also been validated as an effective prognostic factor in various cancers, including UTUC $[12,13]$. Two studies suggested that the combination of SII and PNI may help identify osteosarcoma and esophageal squamous cell carcinoma patients with poor prognosis $[9,10]$; however, its independent association with UTUC patients' survival is not reported. This study aimed to explore the associations of the preoperative SII, NLR, PLR, MLR, and PNI with clinicopathologic variables and to identify the predictive ability of individual or combined indicators in patients with UTUC following RNU.

\section{Materials and Methods}

\section{Patients and study design}

Between March 2006 and August 2015, 310 eligible patients with diagnosed UTUC (pathological T1-4N0-1M0) at the First Affiliated Hospital of Wenzhou Medical University were retrospectively enrolled as the training cohort. In addition, 323 patients with UTUC from The Third Clinical Institute Affiliated to Wenzhou Medical University, People's Hospital of Wenzhou diagnosed between July 2004 and December 2016 were retrospectively enrolled as the validation cohort. The exclusion criteria were as follows: (1) patients who underwent palliative surgery instead of RNU; (2) patients with kidney transplantation before surgery; (3) patients with evidence of metastatic disease at the time of surgery; (4) patients with incomplete preoperative medical information; and (5) patients with relevant comorbidities affecting systemic inflammatory response markers (i.e., chronic liver disease, immunosuppression, cytotoxic medications, leukemia, lymphoma, autoimmune diseases, and chronic inflammatory diseases). None of the enrolled patients were treated with neoadjuvant chemotherapy, radiotherapy, or any other anti-tumor therapy. This study was approved by the ethics committee of the First Affiliated Hospital of Wenzhou Medical University and The Third Clinical Institute Affiliated to Wenzhou Medical University, People's Hospital of Wenzhou and was conducted according to the Declaration of Helsinki. All patients agreed to participate in our study and provided written informed consent.

\section{Definitions of the systemic immune-inflammation index, prognostic nutritional index, and systemic immune cell prognostic score}

SII and PNI were defined as follows: SII = (neutrophil $\times$ platelet)/lymphocyte; PNI = albumin concentration $(\mathrm{g} / \mathrm{L})+5 \times$ total lymphocyte count $\left(10^{9} / \mathrm{L}\right)$. NLR, PLR, and MLR were calculated as the cell ratios of neutrophil/lymphocyte, platelet/ lymphocyte, and monocyte/lymphocyte, respectively. The optimal cutoff values of SII, PNI, NLR, PLR, and MLR in the training cohort were determined by receiver operating characteristic (ROC) curves analysis with overall survival (OS) as the endpoint. 


\section{Statistical analysis}

All data were analyzed using IBM SPSS Statistics for Windows, (version, 25.0, IBM Corp., Armonk, NY) and $\mathrm{R}$ software (Version 3.6.0) with the packages rms, Hmisc, and ggplot. Comparisons between variables were evaluated by Student's t-tests (for normallydistributed continuous variables), Mann-Whitney U test (non-normally distributed data), Pearson's chi-square tests, or Fisher's exact tests. The Kaplan-Meier method was used to estimate the differences in survival rates. Univariate and multivariate Cox proportional hazards regressions were conducted to evaluate the prognostic significance of each variable with respect to OS, CSS, and RFS. The significant predictors in multivariate analysis were included in the nomogram construction. The performance and predictive ability of the nomogram were evaluated by calibration plot, concordance index (c-index), and ROC. All $P$-values were two-tailed, and $P<0.05$ was considered statistically significant.

\section{Results}

\section{Basic patient characteristics}

A total of 253 and 272 patients were included in the training and validation cohorts, respectively. The baseline characteristics of the included cases are summarized in Table S1 and Table 1. The training cohort consisted of 180 men $(71.1 \%)$ and 73 women $(28.9 \%)$ with a mean age of $67.6 \pm 10.5$ years. The median follow-up duration was 33.8 (interquartile range [IQR] 16.7-64.4) months. During the follow-up, $93(36.8 \%)$ patients died, $73(28.9 \%)$ of which died of cancer, and 101 (39.9\%) patients experienced tumor recurrence after surgery. The validation cohort consisted of 182 men (66.9\%) and 90 women (33.1\%). The mean age and median follow-up duration were $65.9 \pm 10.3$ years and 44.6 (IQR 26.8-65.3) months, respectively. During the follow-up, 85 (31.3\%) patients died, $66(24.2 \%)$ of whom died of cancer, and $90(33.1 \%)$ patients experienced tumor recurrence after surgery. There were significant differences between the two cohorts in BMI, surgical approach, anemia, CKD stage, and adjuvant therapy (all $P$-values <0.05). The remaining factors were comparable between the two cohorts (Table S1). The optimal cutoff values of SII, PNI, NLR, PLR, and MLR were $672.44,47.83,2.53,126.88$ and 0.35 (Figure 1). The area under the curve (AUC) values of SII, PNI, NLR, PLR, and MLR were 0.647 (0.577-0.717), 0.596 (0.523-0.669), 0.633 (0.562-0.704), 0.646 (0.578-0.714), and $0.627(0.556-0.698)$, respectively.

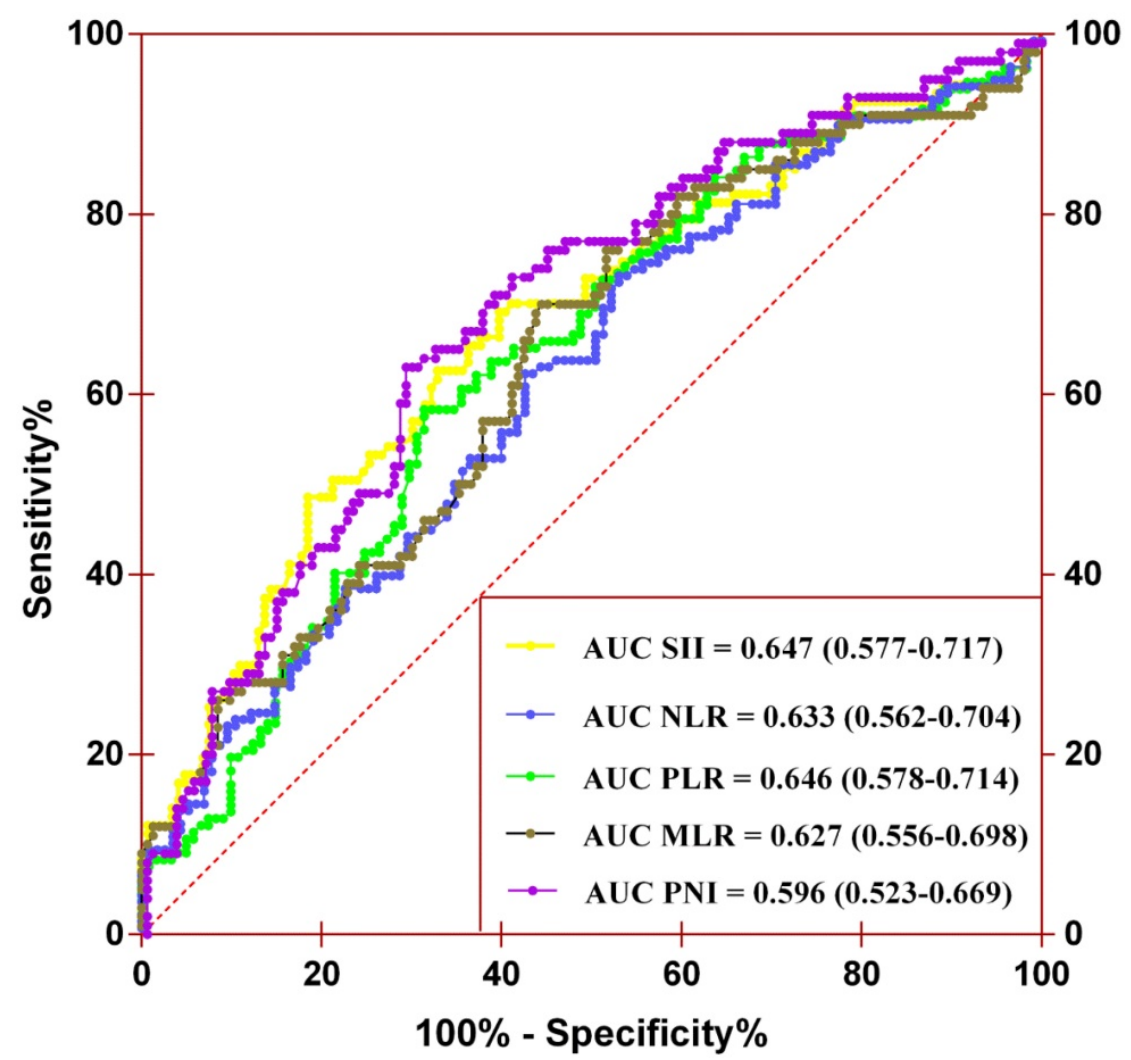

Figure 1. Determination of the optimal cutoff values for SII, NLR, PLR, MLR, and PNI by performing the ROC analysis. 
Table 1. Characteristics of training and validation cohorts according to SII or PNI

\begin{tabular}{|c|c|c|c|c|c|c|c|c|c|c|c|c|}
\hline \multirow[t]{3}{*}{ Variable } & \multicolumn{6}{|c|}{ Training cohort $(\mathrm{n}=253)$} & \multicolumn{6}{|c|}{ Validation cohort $(\mathrm{n}=272)$} \\
\hline & \multicolumn{3}{|l|}{ SII } & \multicolumn{3}{|l|}{ PNI } & \multicolumn{3}{|l|}{ SII } & \multicolumn{3}{|l|}{ PNI } \\
\hline & $\begin{array}{l}\geq 672.44 \\
(n=107)\end{array}$ & $\begin{array}{l}<672.44 \\
(n=146)\end{array}$ & $P$-value & $\begin{array}{l}\geq 47.83 \\
(n=153)\end{array}$ & $\begin{array}{l}<47.83 \\
(\mathrm{n}=100)\end{array}$ & $P$-value & $\begin{array}{l}\geq 672.44 \\
(n=107)\end{array}$ & $\begin{array}{l}<672.44 \\
(n=165)\end{array}$ & $P$-value & $\begin{array}{l}\geq 47.83 \\
(n=126)\end{array}$ & $\begin{array}{l}<47.83 \\
(\mathrm{n}=146)\end{array}$ & $P$-value \\
\hline $\begin{array}{l}\text { Age } \\
\text { (>65 vs } \leq 65 \text { years })\end{array}$ & $69 / 38$ & $92 / 54$ & 0.810 & $86 / 67$ & $75 / 25$ & $0.002 *$ & $66 / 41$ & $92 / 73$ & 0.333 & $59 / 67$ & $99 / 47$ & $<0.001^{*}$ \\
\hline $\begin{array}{l}\text { Gender } \\
\text { (Male vs Female) }\end{array}$ & $81 / 26$ & $99 / 47$ & 0.171 & $107 / 46$ & $73 / 27$ & 0.599 & $79 / 28$ & $103 / 62$ & 0.051 & $87 / 39$ & $95 / 51$ & 0.487 \\
\hline $\begin{array}{l}\text { ASA grade } \\
(\geq 3 \text { vs }<3)\end{array}$ & $27 / 80$ & $34 / 112$ & 0.721 & $28 / 125$ & $33 / 67$ & $0.008^{*}$ & $22 / 85$ & $23 / 142$ & 0.151 & $16 / 110$ & $29 / 117$ & 0.113 \\
\hline $\begin{array}{l}\mathrm{BMI}(\geq 25 \text { vs }<25 \\
\left.\mathrm{Kg} / \mathrm{m}^{2}\right)\end{array}$ & $10 / 97$ & $38 / 108$ & $0.001^{*}$ & $39 / 114$ & $9 / 91$ & $0.001^{*}$ & $30 / 77$ & $61 / 104$ & 0.127 & $44 / 82$ & $47 / 99$ & 0.634 \\
\hline $\begin{array}{l}\text { Hydronephrosis } \\
\text { (Yes vs No) }\end{array}$ & $74 / 33$ & $94 / 52$ & 0.427 & $97 / 56$ & $71 / 29$ & 0.211 & $77 / 30$ & $110 / 55$ & 0.357 & $75 / 51$ & $112 / 34$ & $0.002 *$ \\
\hline $\begin{array}{l}\text { Surgical approach } \\
\text { (laparoscopic vs } \\
\text { open) }\end{array}$ & $28 / 79$ & $57 / 89$ & $0.032^{*}$ & $55 / 98$ & $30 / 70$ & 0.327 & $91 / 16$ & $154 / 11$ & $0.026^{*}$ & $119 / 7$ & $126 / 20$ & $0.025^{*}$ \\
\hline NLR, Mean \pm SD & $5.22 \pm 3.79$ & $2.14 \pm 0.83$ & $<0.001^{*}$ & $2.62 \pm 1.43$ & $4.70 \pm 4.06$ & $<0.001^{*}$ & $5.02 \pm 2.86$ & $2.03 \pm 0.81$ & $<0.001^{*}$ & $3.98 \pm 2.81$ & $2.32 \pm 1.33$ & $<0.001^{*}$ \\
\hline PLR, Mean \pm SD & $\begin{array}{l}216.49 \pm \\
110.38\end{array}$ & $\begin{array}{l}109.59 \pm \\
32.75\end{array}$ & $<0.001^{*}$ & $124.43 \pm 50.51$ & $\begin{array}{l}201.28 \pm \\
119.24\end{array}$ & $<0.001^{*}$ & $\begin{array}{l}184.34 \pm \\
78.49\end{array}$ & $\begin{array}{l}110.01 \pm \\
36.07\end{array}$ & $<0.001^{*}$ & $\begin{array}{l}164.17 \pm \\
75.16\end{array}$ & $\begin{array}{l}110.38 \pm \\
41.00\end{array}$ & $<0.001^{*}$ \\
\hline MLR, Mean \pm SD & $0.52 \pm 0.36$ & $0.26 \pm 0.10$ & $<0.001^{*}$ & $0.28 \pm 0.13$ & $0.51 \pm 0.37$ & $<0.001^{*}$ & $0.46 \pm 0.28$ & $0.26 \pm 0.12$ & $<0.001^{*}$ & $0.41 \pm 0.26$ & $0.25 \pm 0.11$ & $<0.001^{*}$ \\
\hline $\begin{array}{l}\text { Anemia } \\
\text { (Yes vs No) }\end{array}$ & $61 / 46$ & $46 / 61$ & $<0.001^{*}$ & $43 / 110$ & $64 / 36$ & $<0.001$ & $44 / 63$ & $36 / 129$ & $0.001^{*}$ & $24 / 102$ & $56 / 90$ & $<0.001^{*}$ \\
\hline $\begin{array}{l}\text { Hypoproteinemia } \\
\text { (Yes vs No) }\end{array}$ & $16 / 91$ & $6 / 140$ & $0.002^{*}$ & $1 / 152$ & $21 / 79$ & $<0.001$ & $13 / 94$ & $10 / 155$ & 0.078 & $0 / 126$ & $23 / 123$ & $<0.001^{*}$ \\
\hline CKD stage & & & $0.041^{*}$ & & & $<0.001^{*}$ & & & 0.183 & & & 0.677 \\
\hline CKD 1 & 8 & 19 & & 25 & 2 & & 29 & 35 & & 31 & 33 & \\
\hline CKD 2 & 30 & 56 & & 57 & 29 & & 39 & 51 & & 37 & 53 & \\
\hline CKD 3 & 53 & 61 & & 64 & 50 & & 32 & 71 & & 51 & 52 & \\
\hline CKD 4 & 11 & 9 & & 6 & 14 & & 7 & 8 & & 7 & 8 & \\
\hline CKD 5 & 5 & 1 & & 1 & 5 & & 0 & 0 & & 0 & 0 & \\
\hline $\begin{array}{l}\text { Tumor size } \\
(\geq 3 \text { vs }<3, \mathrm{~cm})\end{array}$ & $46 / 61$ & $50 / 96$ & 0.157 & $55 / 98$ & $41 / 59$ & 0.418 & $46 / 61$ & $50 / 115$ & $0.032^{*}$ & $30 / 96$ & $66 / 80$ & $<0.001^{*}$ \\
\hline Tumor site & & & 0.677 & & & 0.246 & & & 0.052 & & & 0.847 \\
\hline Pelvicalyceal & 69 & 94 & & 100 & 63 & & 60 & 89 & & 71 & 78 & \\
\hline Ureter & 32 & 47 & & 49 & 30 & & 36 & 70 & & 48 & 58 & \\
\hline Both & 6 & 5 & & 4 & 7 & & 11 & 6 & & 7 & 10 & \\
\hline $\begin{array}{l}\text { Multifocality } \\
\text { (Yes vs No) }\end{array}$ & $27 / 80$ & $21 / 125$ & $0.030^{*}$ & $25 / 128$ & $23 / 77$ & 0.187 & $25 / 82$ & $40 / 125$ & 0.868 & $26 / 100$ & $39 / 107$ & 0.241 \\
\hline Pathologic T stage & & & $<0.001^{*}$ & & & $<0.001^{*}$ & & & $<0.001^{*}$ & & & $0.017^{*}$ \\
\hline$\geq \mathrm{pT} 3$ & 53 & 54 & & 39 & 47 & & 62 & 52 & & 41 & 73 & \\
\hline$<\mathrm{pT} 3$ & 33 & 113 & & 114 & 53 & & 45 & 113 & & 85 & 73 & \\
\hline N stage (N1 vs N0) & $20 / 87$ & $4 / 142$ & $<0.001^{*}$ & $10 / 143$ & $14 / 86$ & $0.048^{*}$ & $12 / 95$ & $5 / 160$ & $0.006^{*}$ & $6 / 120$ & $11 / 135$ & 0.346 \\
\hline $\begin{array}{l}\text { Tumor grade } \\
(\geq 3 \text { vs }<3)\end{array}$ & $87 / 20$ & $108 / 38$ & 0.170 & $116 / 37$ & $79 / 21$ & 0.556 & $84 / 23$ & $113 / 52$ & 0.071 & $84 / 42$ & $113 / 33$ & $0.048^{*}$ \\
\hline LVI (Yes vs No) & $28 / 79$ & $13 / 133$ & $<0.001^{*}$ & $16 / 137$ & $25 / 75$ & $0.002 *$ & $24 / 83$ & $14 / 151$ & $0.001^{*}$ & $17-109$ & $21 / 125$ & 0.833 \\
\hline $\begin{array}{l}\text { Adjuvant therapy } \\
\text { (Yes vs No) }\end{array}$ & $18 / 89$ & $10 / 136$ & $0.012^{*}$ & $17 / 136$ & $11 / 89$ & 0.978 & $35 / 72$ & $39 / 126$ & 0.100 & $36 / 90$ & $38 / 108$ & 0.638 \\
\hline $\begin{array}{l}\text { Follow-up } \\
\text { duration, months, } \\
\text { median (IQR) }\end{array}$ & $\begin{array}{l}20.30 \\
(10.90-46.60)\end{array}$ & $\begin{array}{l}42.70 \\
(24.35-69.48)\end{array}$ & $<0.001^{*}$ & $\begin{array}{l}43.80 \\
(22.75-70.70)\end{array}$ & $\begin{array}{l}24.45 \\
(10.90-39.68)\end{array}$ & $<0.001^{*}$ & $\begin{array}{l}32.90 \\
(16.90-52.00)\end{array}$ & $\begin{array}{l}52.20 \\
(33.60-73.50)\end{array}$ & $<0.001^{*}$ & $\begin{array}{l}51.65 \\
(31.85-66.05)\end{array}$ & $\begin{array}{l}37.10 \\
(24.00-64.08)\end{array}$ & $<0.001^{*}$ \\
\hline $\begin{array}{l}\text { All-cause death, } \\
\mathrm{n}(\%)\end{array}$ & $59(55.14 \%)$ & $34(23.29 \%)$ & $<0.001^{*}$ & $40(25.16 \%)$ & $53(53.00 \%)$ & $<0.001^{*}$ & $53(49.53 \%)$ & $32(19.39 \%)$ & $<0.001^{*}$ & $19(15.08 \%)$ & $66(45.21 \%)$ & $<0.001^{*}$ \\
\hline $\begin{array}{l}\text { Cancer-specific } \\
\text { death, } \mathrm{n}(\%)\end{array}$ & $48(44.86 \%)$ & $25(17.12 \%)$ & $<0.001^{*}$ & $30(18.87 \%)$ & $43(43.00 \%)$ & $<0.001^{*}$ & $45(42.6 \%)$ & $21(12.73 \%)$ & $<0.001^{*}$ & $16(12.70 \%)$ & $50(34.25 \%)$ & $<0.001^{*}$ \\
\hline $\begin{array}{l}\text { Recurrence after } \\
\text { surgery, } \mathrm{n}(\%)\end{array}$ & $\begin{array}{l}55 \\
(51.40 \%)\end{array}$ & $\begin{array}{l}46 \\
(31.51 \%)\end{array}$ & $<0.001^{*}$ & $\begin{array}{l}47 \\
(30.72 \%)\end{array}$ & $\begin{array}{l}54 \\
(54.00 \%)\end{array}$ & $<0.001$ & $\begin{array}{l}50 \\
(46.73 \%)\end{array}$ & $\begin{array}{l}40 \\
(24.24 \%)\end{array}$ & $<0.001^{*}$ & $\begin{array}{l}30 \\
(23.81 \%)\end{array}$ & $\begin{array}{l}60 \\
(41.10 \%)\end{array}$ & $0.003^{*}$ \\
\hline
\end{tabular}

Note: *statistically significant;

Abbreviations: ASA; American Society of Anesthesiologists; BMI, body mass index; SII, systemic immune-inflammation index; PNI, prognostic nutritional index; NLR, neutrophil-to-lymphocyte ratio; PLR, platelet-to-lymphocyte ratio; MLR, monocyte-to-lymphocyte ratio; CKD, chronic kidney disease; LVI, lymphovascular invasion; IQR, interquartile range.

Table 1 shows the correlations between inflammatory-based biomarkers (SII and PNI) and patient clinicopathologic parameters in the two cohorts. In the training cohort, SII and PNI were closely related to age, American Society of Anesthesiologists (ASA) grade, body mass index (BMI), surgical approach, NLR, PLR, MLR, anemia, hypoproteinemia, chronic kidney disease (CKD) stage, multifocality, pathologic $\mathrm{T}$ stage, $\mathrm{N}$ stage, lymphovascular invasion (LVI), and adjuvant therapy (All $P$-values $<0.05$ ). In the validation cohort, SII and PNI were significantly correlated with age, hydronephrosis, surgical approach, NLR, PLR, MLR, anemia, hypoproteinemia, tumor size, pathologic $\mathrm{T}$ stage, N stage, tumor grade, and LVI (All $P$-values < 0.05). 
A

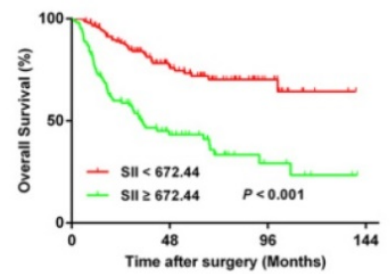

D

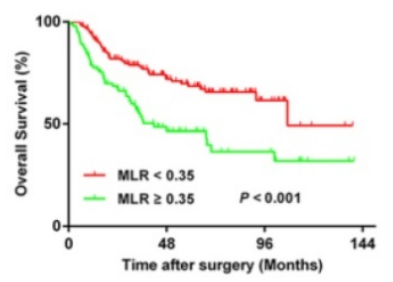

F

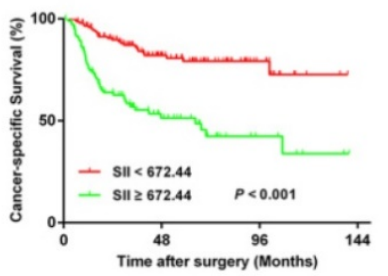

I

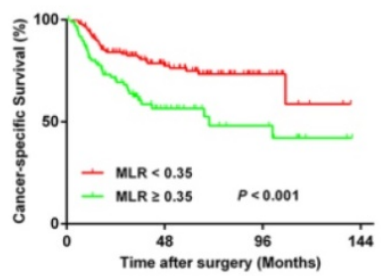

K

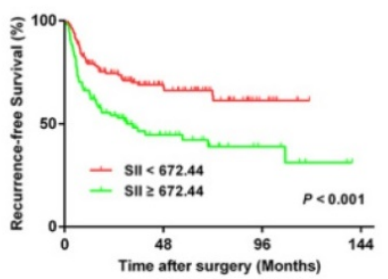

$\mathbf{N}$

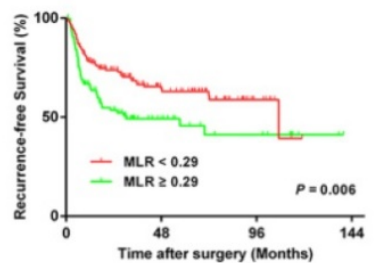

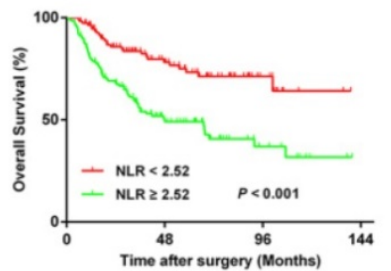

$\mathbf{E}$

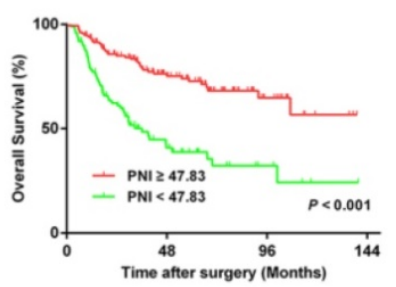

G

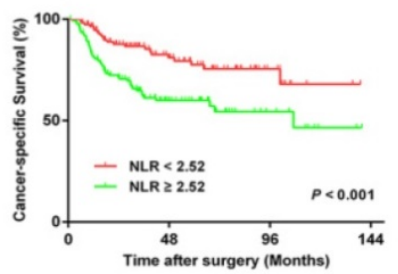

$\mathbf{J}$

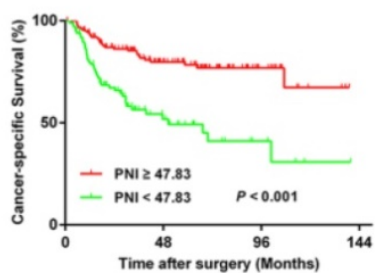

$\mathbf{L}$

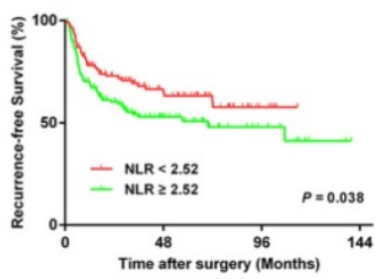

o

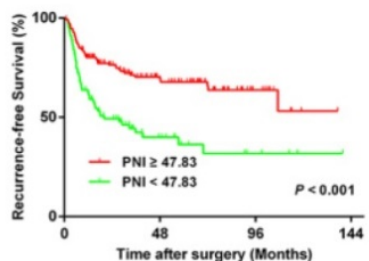

C

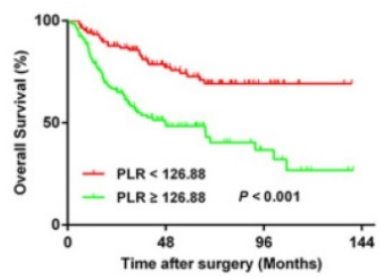

H

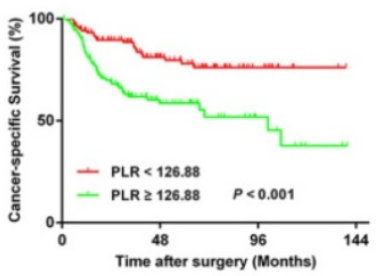

M

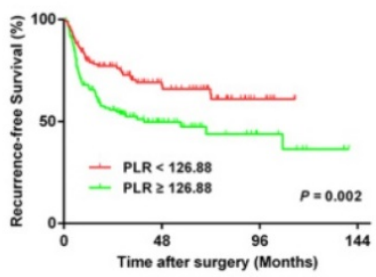

Figure 2. Kaplan-Meier curves for OS, CSS, and RFS in UTUC patients stratified by SII, NLR, PLR, MLR, and PNI in the training cohort.

\section{Association with UTUC prognosis}

Kaplan-Meier survival analysis indicated that patients in the training cohort with higher SII, NLR,
PLR, and MLR had poorer OS, CSS, and RFS (All $P$-values < 0.05) (Figure 2). Lower OS, CSS, and RFS were observed in patients with lower PNI (All 
$P$-values < 0.05) (Figure 2). These results were confirmed in the validation cohort (Figure S1). Furthermore, univariate and multivariate analyses revealed that age, tumor size, pathologic $\mathrm{T}$ stage, and $\mathrm{N}$ stage were significant risk factors associated with OS, CSS, and RFS in the training cohort (All $P$-values $<0.05$ ) (Table S2-S5). The SII and PNI were independent predictors of OS, CSS, and RFS in the training cohort and validation cohort (Table S3). The significant influence of SII and PNI on OS, CSS, and RFS were further confirmed when running multivariate analysis for SII and PNI, respectively (Table S4-S5).

\section{The prognostic value of the combination of SII and PNI in patients with UTUC following RNU}

We further evaluated the predictive value of the combination of SII and PNI (SII-PNI). The patients were grouped as follows: low SII + high PNI, high SII + high PNI, low SII + low PNI, and high SII + low PNI. Figure 3 and Figure S2 show that patients with high SII + low PNI had the poorest OS, CSS, and RFS (All $P$-values < 0.05). A multivariate analysis was performed to investigate the effects of different SII and PNI combinations on OS, CSS, and RFS. Patients with high SII + low PNI had significantly worse OS, CSS, and RFS than those with low SII + high PNI in both the training cohort (OS: hazard ratio $(\mathrm{HR})=3.853$;

A

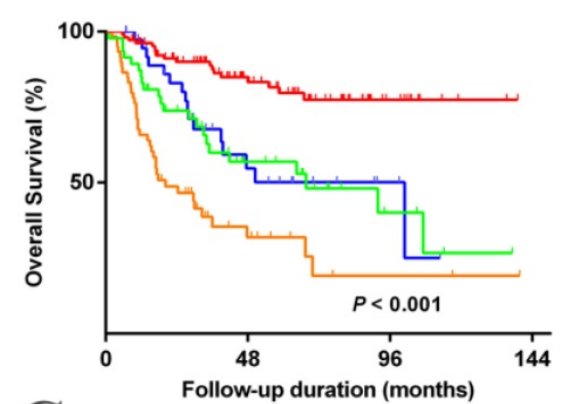

C

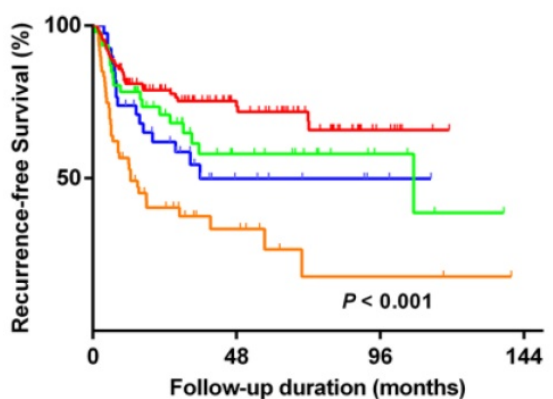

95\% confidence interval (CI), 1.588-9.350; $P=0.003$; CSS: $\mathrm{HR}=5.197 ; 95 \% C I, 1.805-14.959 ; P=0.002$; RFS: $\mathrm{HR}=2.915 ; 95 \% \mathrm{CI}, 1.276-6.659 ; P=0.011)$ and validation cohort (OS: $\mathrm{HR}=5.065 ; 95 \% \mathrm{CI}$, 1.798-14.269; $P=0.002$; CSS: $\mathrm{HR}=6.295 ; 95 \% \mathrm{CI}$, 1.864-21.265; $P=0.003$; RFS: $H R=1.991 ; 95 \% C I$, 1.814-4.872; $P=0.031$ ) (Table 2). In addition, compared to SII or PNI alone and other inflammatory factors or clinical parameters, SII-PNI achieved the largest AUC (Figure 1 and Figure 7G), indicating that simultaneously high SII and low PNI values had better accurate predictive ability for predicting survival and could be identified as a prognostic staging tool for patients with UTUC.

\section{Establishment of nomograms and comparison of prognostic ability}

The identified independent predictors from the multivariate analysis were used to construct nomograms for OS, CSS, and RFS (Figure 4A, Figure 5A, Figure 6A, Figure S3A, Figure S4A, and Figure $\mathrm{S} 5 \mathrm{~A})$. The calibration plots of the three- and five- year survival probabilities showed that the predicted probability was highly consistent with the actual survival probability, indicating that the nomograms were well-calibrated (Figure 4B-C, Figure 5B-C, Figure 6B-C, Figure S3 B-C, Figure S4 B-C, and Figure S5 B-C).

\section{B}
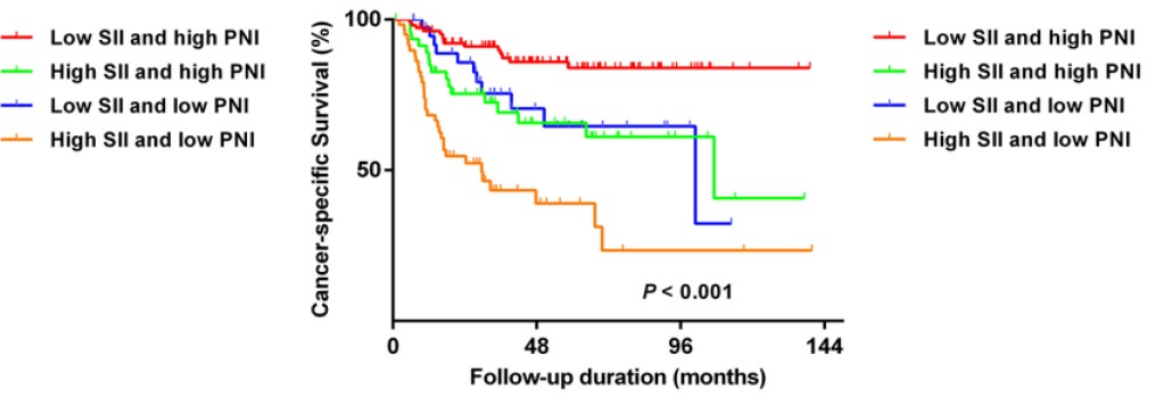

- Low SII and high PNI

- High SII and high PNI

- Low SII and low PNI

_ High SII and low PNI

Figure 3. Kaplan-Meier analysis for OS, CSS, and RFS in patients with UTUC who was divided into 4 groups based on SII-PNI in the training cohort. 
A

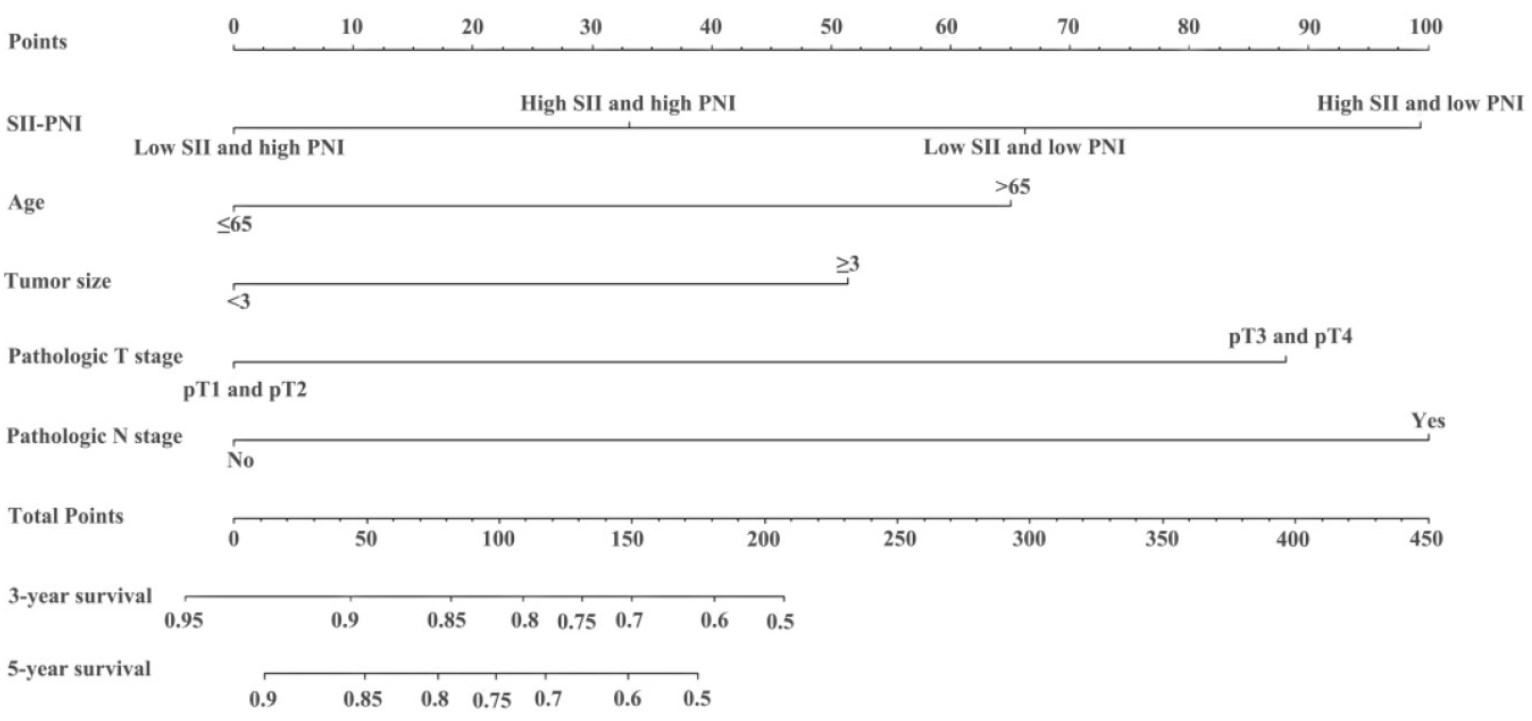

B

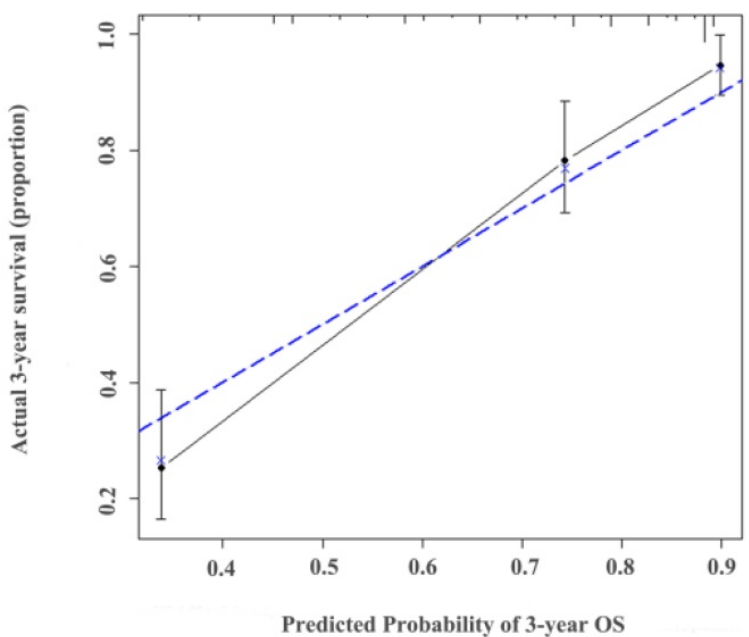

C

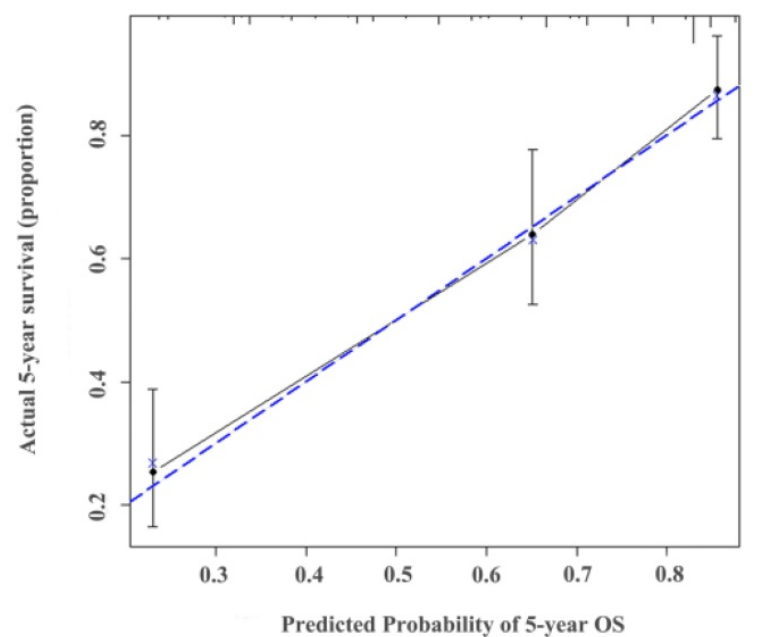

Figure 4. Construction of nomograms to predict OS (A) in patients with UTUC after surgery and Calibration curve for predicting 3-and 5-year survival of OS (B and C) in the training cohort.

As shown in Table 3, the c-indexes for nomograms of OS, CSS, and RFS in the training cohort increased when SII-PNI was incorporated. SII-PNI combined with pathologic $\mathrm{T}$ stage, or $\mathrm{N}$ stage in the training cohort, respectively, had higher c-index values than those for SII or other parameters alone. In addition, by incorporating SII-PNI into developed models, the AUC and c-index of the nomograms increased in the training cohort (Table 3 and Figure 7). Moreover, these results were confirmed in the validation cohort (Table 3 and Figure 7). These findings indicated the ability of this new biomarker to improve the prognostic accuracy for patients with UTUC.

\section{Discussion}

An accumulating number of studies have investigated the potential biomarkers to predict the prognosis of patients with UTUC to help urologists choose optimal treatments for individual patients. In the present study, a higher SII was independently associated with poorer prognosis in terms of shorter OS, CSS, and RFS, while a relatively higher PNI was associated with better OS, CSS, and RFS. The cooccurrence of higher SII and lower PNI was a strong independent prognostic factor of OS, CSS, and RFS, which identified patients with higher risk of mortality. In addition, with the largest AUC, the predictive ability of SII-PNI was superior to that of SII and PNI alone for predicting OS, CSS, and RFS. Most importantly, the predictive accuracy of an established nomogram was improved with increased c-index and AUC when incorporating SII-PNI. To our knowledge, this is the first report to investigate SII-PNI as a meaningful predictor for patients with UTUC. 
Table 2. Multivariate analysis of variables for the prediction of survival outcomes in training and validation cohorts when SII-PNI was incorporated

\begin{tabular}{|c|c|c|c|c|c|c|c|c|c|}
\hline \multirow[t]{2}{*}{ Variables } & \multicolumn{3}{|c|}{ Overall survival } & \multicolumn{3}{|c|}{ Cancer-specific survival } & \multicolumn{3}{|c|}{ Recurrence-free survival } \\
\hline & HR & $95 \% \mathrm{CI}$ & $P$ value & HR & $95 \% \mathrm{CI}$ & $P$ value & HR & $95 \% \mathrm{CI}$ & $P$ value \\
\hline \multicolumn{10}{|l|}{ Training cohort } \\
\hline Age ( $>65$ vs $\leq 65$ years) & 2.086 & $1.025-5.100$ & $0.043^{*}$ & 1.811 & $1.055-3.107$ & $0.031^{*}$ & 1.536 & $0.991-2.381$ & 0.055 \\
\hline \multicolumn{10}{|l|}{ SII-PNI } \\
\hline Low SII+high PNI & 1.000 & Reference & 1.000 & 1.000 & Reference & 1.000 & 1.000 & Reference & 1.000 \\
\hline High SII+high PNI vs Low SII+high PNI & 2.481 & $1.058-5.817$ & $0.037^{*}$ & 3.011 & $1.103-8.224$ & $0.032^{*}$ & 1.626 & $0.722-3.662$ & 0.241 \\
\hline Low SII+low PNI vs Low SII+high PNI & 2.529 & $1.205-5.310$ & $0.014^{*}$ & 2.390 & $0.998-5.723$ & 0.050 & 1.810 & $0.948-3.456$ & 0.072 \\
\hline High SII+low PNI vs Low SII+high PNI & 3.853 & $1.588-9.350$ & $0.003^{*}$ & 5.197 & $1.805-14.959$ & $0.002^{*}$ & 2.915 & $1.276-6.659$ & $0.011^{*}$ \\
\hline $\operatorname{NLR}(\geq 2.53$ vs $<2.53)$ & 0.770 & $0.382-1.550$ & 0.464 & 0.502 & $0.217-1.160$ & 0.107 & 0.555 & $0.284-1.083$ & 0.084 \\
\hline $\operatorname{PLR}(\geq 126.88$ vs $<126.88)$ & 1.373 & $0.767-2.456$ & 0.286 & 1.332 & $0.691-2.566$ & 0.392 & 1.275 & $0.746-2.177$ & 0.375 \\
\hline $\operatorname{MLR}(\geq 0.35 \mathrm{vs}<0.35)$ & 0.797 & $0.484-1.310$ & 0.371 & 0.804 & $0.455-1.422$ & 0.454 & 0.934 & $0.571-1.526$ & 0.784 \\
\hline Tumor size $(\geq 3$ vs $<3$ ) & 1.722 & $1.117-2.654$ & $0.014^{*}$ & 1.751 & $1.073-2.857$ & $0.025^{*}$ & 1.471 & $0.977-2.216$ & 0.065 \\
\hline Pathologic T stage ( $\geq$ pT3 vs $<$ pT3) & 2.476 & $1.498-4.092$ & $<0.001^{*}$ & 2.837 & $1.578-5.100$ & $<0.001^{*}$ & 1.686 & $1.029-2.764$ & $0.038^{*}$ \\
\hline N stage (N1 vs N0) & 2.286 & $1.025-5.100$ & $0.043^{*}$ & 2.062 & $1.719-5.919$ & $0.048^{*}$ & 2.285 & $1.022-5.105$ & $0.044^{*}$ \\
\hline Tumor grade $(\geq 3$ vs $<3$ ) & 1.355 & $0.630-2.918$ & 0.437 & 2.062 & $0.719-5.919$ & 0.178 & 1.560 & $0.822-2.959$ & 0.174 \\
\hline LVI (Yes vs No) & 1.580 & $0.759-3.290$ & 0.222 & 2.071 & $0.958-4.477$ & 0.064 & 1.333 & $0.644-2.758$ & 0.439 \\
\hline \multicolumn{10}{|l|}{ Validation cohort } \\
\hline Age ( $>65$ vs $\leq 65$ years) & 1.056 & $0.647-1.724$ & 0.828 & 0.876 & $0.511-1.500$ & 0.629 & 0.984 & $0.621-1.558$ & 0.945 \\
\hline \multicolumn{10}{|l|}{ SII-PNI } \\
\hline Low SII+high PNI & 1.000 & Reference & 1.000 & 1.000 & Reference & 1.000 & 1.000 & Reference & 1.000 \\
\hline High SII+high PNI vs Low SII+high PNI & 2.963 & $0.990-8.865$ & 0.052 & 3.867 & $1.143-13.085$ & $0.030^{*}$ & 0.982 & $0.365-2.644$ & 0.672 \\
\hline Low SII+low PNI vs Low SII+high PNI & 2.791 & $1.266-6.151$ & $0.011^{*}$ & 2.464 & $0.947-6.414$ & 0.065 & 1.059 & $0.537-2.086$ & 0.369 \\
\hline High SII+low PNI vs Low SII+high PNI & 5.065 & $1.798-14.269$ & $0.002^{*}$ & 6.295 & $1.864-21.265$ & $0.003^{*}$ & 1.991 & $1.814-4.872$ & $0.031^{*}$ \\
\hline $\operatorname{NLR}(\geq 2.53$ vs $<2.53)$ & 0.592 & $0.270-1.300$ & 0.191 & 0.580 & $0.231-1.453$ & 0.245 & 0.931 & $0.444-1.951$ & 0.850 \\
\hline PLR $(\geq 126.88$ vs $<126.88)$ & 1.517 & $0.846-2.720$ & 0.162 & 1.374 & $0.734-2.575$ & 0.321 & 1.301 & $0.731-2.31$ & 0.370 \\
\hline MLR $(\geq 0.35$ vs $<0.35)$ & 1.561 & $0.907-2.686$ & 0.108 & 1.439 & $0.792-2.614$ & 0.232 & 1.290 & $0.770-2.161$ & 0.333 \\
\hline Tumor size $(\geq 3$ vs $<3)$ & 1.107 & $0.698-1.756$ & 0.666 & 1.140 & $0.676-1.924$ & 0.623 & 1.112 & $0.709-1.744$ & 0.644 \\
\hline Pathologic T stage ( $\geq$ pT3 vs $<$ pT3) & 3.000 & $1.767-5.092$ & $<0.001^{*}$ & 4.621 & $2.396-8.911$ & $<0.001^{*}$ & 3.308 & $1.993-5.491$ & $<0.001^{*}$ \\
\hline $\mathrm{N}$ stage (N1 vs N0) & 2.070 & $1.200-5.228$ & $0.027^{*}$ & 1.831 & $1.085-4.891$ & $0.038^{*}$ & 1.304 & $1.010-3.153$ & $0.045^{*}$ \\
\hline Tumor grade $(\geq 3 \mathrm{vs}<3)$ & 1.763 & $0.896-3.467$ & 0.101 & 1.757 & $0.768-4.019$ & 0.182 & 1.607 & $0.844-3.058$ & 0.149 \\
\hline LVI (Yes vs No) & 1.047 & $0.472-2.327$ & 0.909 & 1.090 & $0.484-2.456$ & 0.835 & 1.332 & $0.664-2.672$ & 0.420 \\
\hline
\end{tabular}

Note: *statistically significant.

Table 3. C-index analysis of the prognostic accuracy of SII-PNI and other variables for OS, CSS, and RFS in training cohort and validation cohort

\begin{tabular}{|c|c|c|c|}
\hline Characteristics & OS & CSS & RFS \\
\hline \multicolumn{4}{|l|}{ Training cohort } \\
\hline Age & $0.566(0.515-0.617)$ & $0.551(0.493-0.609)$ & - \\
\hline SII-PNI & $0.701(0.648-0.754)$ & $0.698(0.638-0.758)$ & $0.638(0.582-0.694)$ \\
\hline Tumor size & $0.567(0.514-0.620)$ & $0.567(0.507-0.627)$ & - \\
\hline Pathologic T stage & $0.689(0.641-0.737)$ & $0.713(0.658-0.765)$ & $0.633(0.585-0.681)$ \\
\hline N stage & $0.619(0.574-0.664)$ & $0.639(0.587-0.691)$ & $0.591(0.553-0.629)$ \\
\hline SII-PNI + Pathologic T stage & $0.760(0.710-0.810)$ & $0.777(0.722-0.832)$ & $0.680(0.626-0.734)$ \\
\hline SII-PNI + N stage & $0.765(0.717-0.813)$ & $0.778(0.725-0.831)$ & $0.688(0.632-0.744)$ \\
\hline Model A & $0.804(0.761-0.847)$ & - & - \\
\hline Model B & $0.780(0.734-0.826)$ & - & - \\
\hline Model C & - & $0.817(0.771-0.863)$ & - \\
\hline Model D & - & $0.802(0.752-0.852)$ & - \\
\hline Model E & - & - & $0.707(0.654-0.760)$ \\
\hline Model F & - & - & $0.669(0.619-0.719)$ \\
\hline \multicolumn{4}{|l|}{ Validation cohort } \\
\hline SII-PNI & $0.698(0.644-0.752)$ & $0.706(0.647-0.765)$ & $0.592(0.526-0.658)$ \\
\hline Pathologic T stage & $0.697(0.648-0.746)$ & $0.727(0.677-0.777)$ & $0.642(0.584-0.700)$ \\
\hline N stage & $0.561(0.521-0.601)$ & $0.555(0.511-0.599)$ & $0.529(0.492-0.566)$ \\
\hline SII-PNI + Pathologic T stage & $0.774(0.729-0.819)$ & $0.798(0.750-0.846)$ & $0.663(0.597-0.729)$ \\
\hline SII-PNI + N stage & $0.722(0.669-0.775)$ & $0.721(0.663-0.779)$ & $0.612(0.547-0.677)$ \\
\hline Model G & $0.783(0.737-0.829)$ & - & - \\
\hline Model H & $0.719(0.668-0.770)$ & - & - \\
\hline Model I & - & $0.803(0.755-0.851)$ & - \\
\hline Model J & - & $0.745(0.694-0.796)$ & - \\
\hline Model K & - & - & $0.670(0.604-0.736)$ \\
\hline Model L & - & - & $0.651(0.590-0.712)$ \\
\hline $\begin{array}{l}\text { Model A }(\text { for OS) }=\text { age }+ \text { SII- } \\
\text { Model C (for CSS) = age + SII } \\
\text { Model E (for RFS) = SII-PNI + } \\
\text { Model H (for OS) = pathologi }\end{array}$ & $\begin{array}{l}\text { hologic T stage + N s } \\
\text { hologic T stage + N } \\
\text { stage; Model F (for } \\
\text { del I (for CSS) = SII- }\end{array}$ & $\begin{array}{l}\text { DS) }=\text { age }+ \text { tumor siz } \\
\text { CSS) = age + tumor } \\
\text { stage + N stage; Mo } \\
\text { stage + N stage; Moc } \\
\Gamma \text { stage + N stage. }\end{array}$ & $\begin{array}{l}\text { age + N stage; } \\
\text { stage + N stage; } \\
\text {-PNI + pathologic T stage + N stage; } \\
\text { hologic T stage + N stage; }\end{array}$ \\
\hline
\end{tabular}


A Points $\quad \begin{array}{lllllllllll}0 & 10 & 20 & 30 & 40 & 50 & 60 & 70 & 80 & 90 & 100\end{array}$

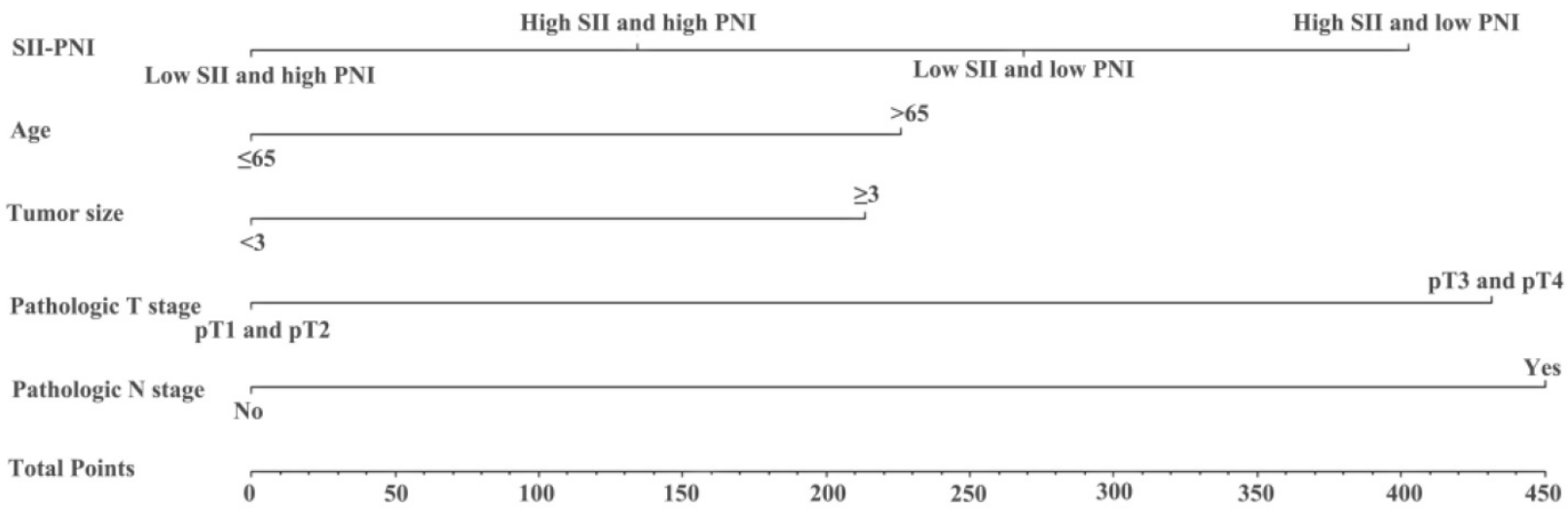

\begin{tabular}{|c|c|c|c|c|c|c|c|c|c|}
\hline \multirow{2}{*}{ 3-year survival } & \multirow[b]{2}{*}{0.95} & \multirow{2}{*}{\multicolumn{2}{|c|}{0.9}} & \multirow[b]{2}{*}{0.85} & \multirow[b]{2}{*}{0.8} & \multirow[b]{2}{*}{0.75} & \multirow[b]{2}{*}{0.7} & \multirow[b]{2}{*}{0.6} & \multirow[b]{2}{*}{0.5} \\
\hline & & & & & & & & & \\
\hline year survival & & 0.9 & 0.85 & 0.8 & 0.75 & 0.7 & 0.6 & $\overrightarrow{0.5}$ & \\
\hline
\end{tabular}

B

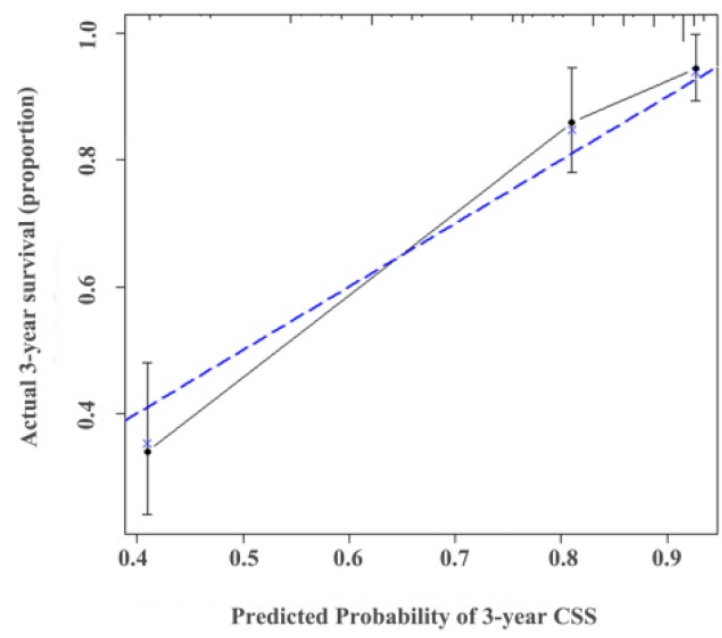

C

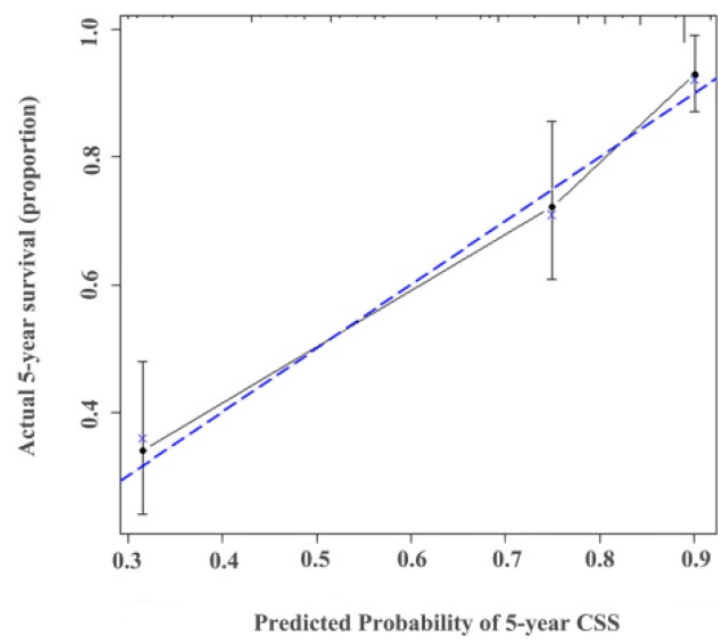

Figure 5. Construction of nomograms to predict CSS (A) in patients with UTUC after surgery and Calibration curve for predicting 3-and 5-year survival of CSS (B and C) in the training cohort.

Accumulating evidence indicates that increased systemic inflammatory response and a low nutritional status play important roles in the tumor progression and metastasis, which influence treatment outcomes, prognosis, and survival $[12,13]$. In recent years, the role of inflammation or nutrition-related factors, including NLR, PLR, albumin levels, and sarcopenia, in malignant tumors have attracted increased attention as significant predictors for various cancers that can reflect tumor' progression $[7,8,14-16]$. In the current study, high SII and low PNI were correlated with old age, larger tumor size, LVI, pathologic T stage, $\mathrm{N}$ stage, and other clinical parameters indicative of an aggressive phenotype, which were consistent with the findings of a previous study. Our study results further demonstrated that elevated SII and decreased PNI were independent risk biomarkers in UTUC patients undergoing RNU.

The mechanisms of the complex interplay among systemic inflammatory response, nutritional status, tumor cell invasion, proliferation, and metastasis remain controversial. Several explanations have been proposed regarding the functions of circulating blood leukocytes, including neutrophils, platelets, and lymphocytes, which are the main contributors in the process of angiogenesis, invasion, and metastasis in the microenvironment of tumor-associated inflammation. First, infiltration of tumor-associated neutrophils may establish the tumor microenvironment by attracting inflammatory factors, 
including vascular endothelial growth factor, reactive oxygen species, and matrix metalloproteinase 9, which promote genetic instability and stimulate angiogenesis [17]. In addition, neutrophils can inactive $\mathrm{T}$ cells and protect cancers cells from immune surveillance [18]. Thus, increased neutrophil counts have tumor-promoting effects, contributing to tumor angiogenesis and metastasis [17, 19, 20]. Second, it is reported that $10-57 \%$ patients with cancer are observed with thrombocytosis [9]. Elevated platelets might induce epithelial-mesenchymal transition of circulating tumor cells [21], shield cancer cells from immune cells cytotoxicity and facilitate the extravasation of cancer cells [22-24], leading to the development and progression of cancer. Third, circulating lymphocytes have anti-tumor effects by secreting cytokines, including interferon (IFN)- $\gamma$ and tumor necrosis factor (TNF)- $\alpha$, and promoting cytotoxic cell death [20]. The activation of the immune response, which can promote a protective response in patients with cancer, mainly depends on the level of lymphocytes, indicating their powerful antitumor properties. In addition, a previous study reported that a high SII was associated with elevated serum levels of inflammatory cytokines and chemokines [25]. Therefore, a high SII level may indicate a significant inflammatory response with increased participation of neutrophils and platelets; increased cytokine and growth factor expression and low immune response with decreased infiltration of lymphocytes. As a result, survival after surgery is poor in patients with increased SII.

A

Points
SII-PNI
Pathologic T stage
Low SII and high PNI
Pathologic N stage
Total Points

B

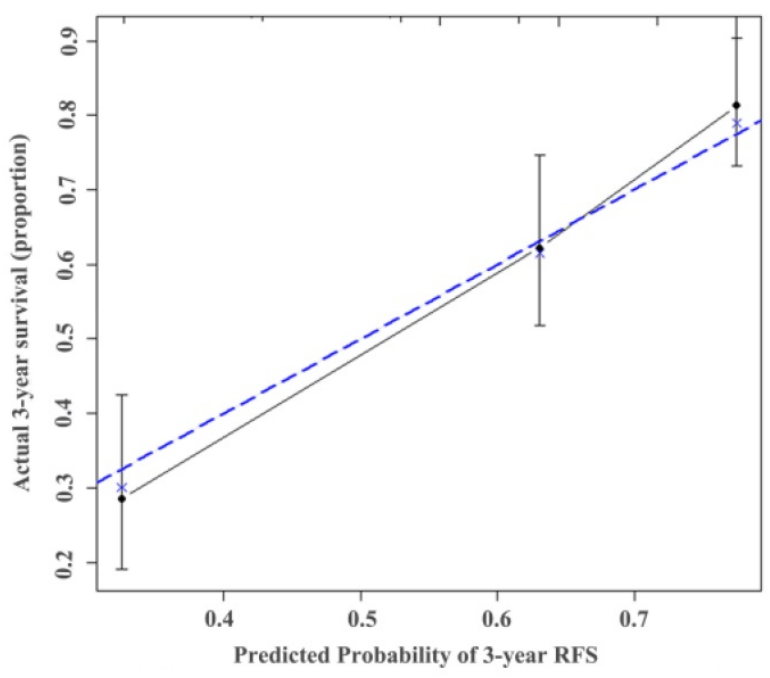

C

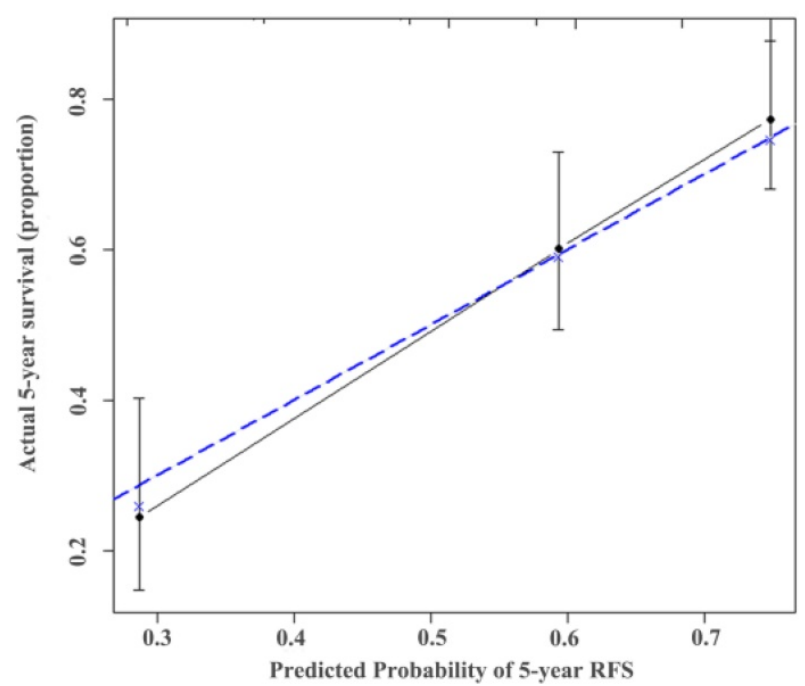

Figure 6. Construction of nomograms to predict RFS (A) in patients with UTUC after surgery and Calibration curve for predicting 3- and 5-year survival of RFS (B and C) in the training cohort. 
A

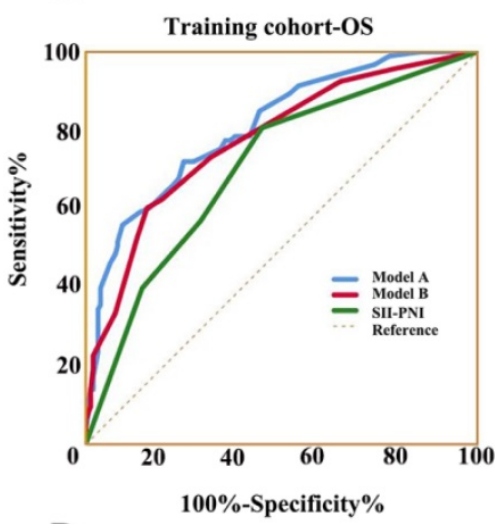

D

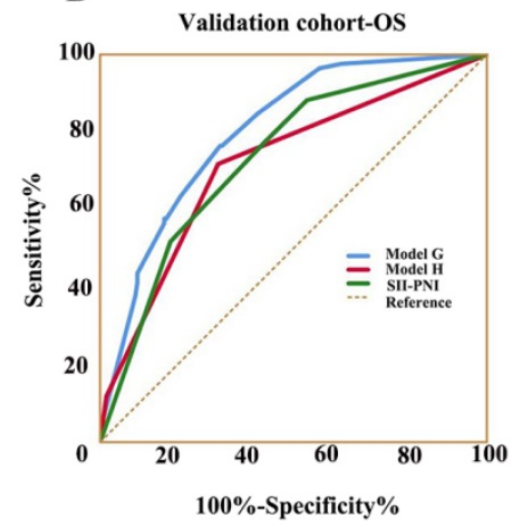

B

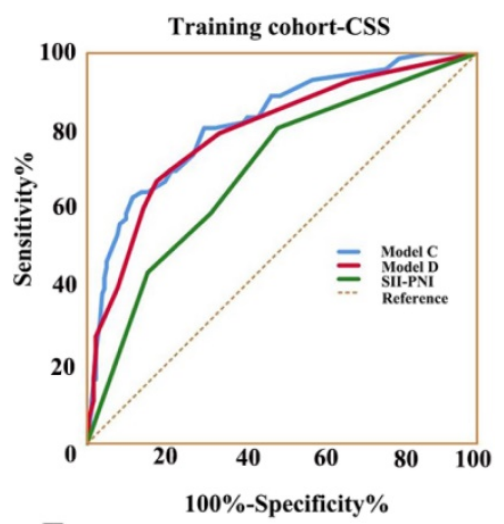

$\mathbf{E}$

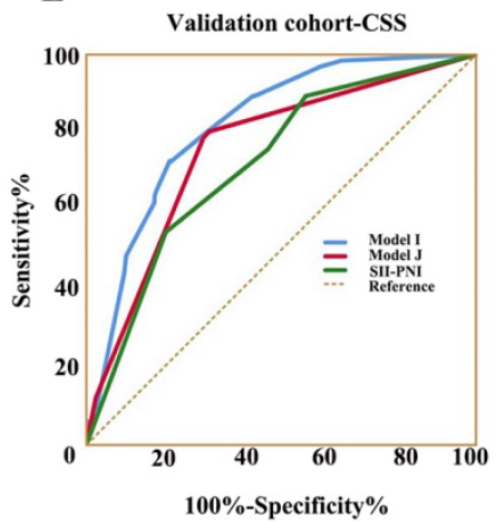

C
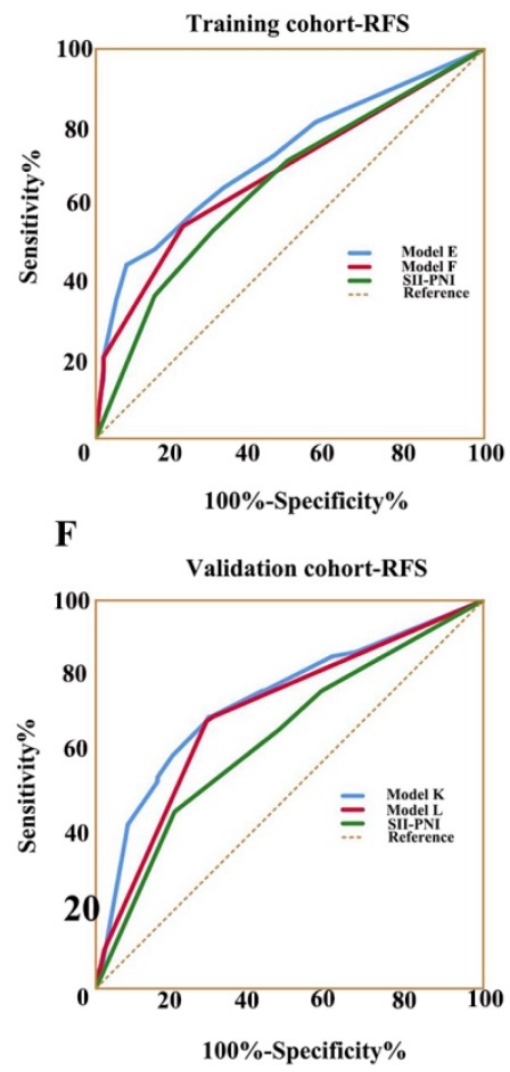

\begin{tabular}{ccccccc}
\hline Model & AUC $(95 \% \mathrm{CI})$ & $\begin{array}{c}\text { Sensitivity\% } \\
(95 \%)\end{array}$ & $\begin{array}{c}\text { Specificity\% } \\
(95 \%)\end{array}$ & Youden index & $\begin{array}{c}\text { Positive } \\
\text { likelihood } \\
\text { ratio }\end{array}$ & $\begin{array}{c}\text { Negative } \\
\text { likelihood } \\
\text { ratio }\end{array}$ \\
\hline Training cohort & & & & & & \\
\hline OS & & & & & & \\
Model A & $0.809(0.754-0.864)$ & $72.0 \%$ & $75.0 \%$ & 0.470 & 2.88 & 0.37 \\
Model B & $0.775(0.715-0.835)$ & $60.2 \%$ & $84.4 \%$ & 0.446 & 3.86 & 0.47 \\
SII-PNI & $0.705(0.639-0.772)$ & $80.6 \%$ & $55.0 \%$ & 0.356 & 1.79 & 0.35 \\
CSS & & & & & & \\
Model C & $0.824(0.766-0.881)$ & $63.0 \%$ & $88.3 \%$ & 0.513 & 5.38 & 0.42 \\
Model D & $0.797(0.735-0.860)$ & $67.1 \%$ & $82.2 \%$ & 0.493 & 3.77 & 0.40 \\
SII-PNI & $0.699(0.628-0.770)$ & $80.8 \%$ & $51.1 \%$ & 0.319 & 1.65 & 0.38 \\
RFS & & & & & & \\
Model E & $0.720(0.654-0.787)$ & $44.6 \%$ & $92.1 \%$ & 0.367 & 5.65 & 0.60 \\
Model F & $0.678(0.608-0.748)$ & $54.5 \%$ & $77.6 \%$ & 0.321 & 2.43 & 0.59 \\
SII-PNI & $0.649(0.579-0.719)$ & $53.5 \%$ & $69.7 \%$ & 0.232 & 1.78 & 0.67 \\
\hline Validation cohort & & & & & & \\
\hline OS & & & & & & \\
Model G & $0.802(0.749-0.855)$ & $76.5 \%$ & $69.0 \%$ & 0.455 & 2.47 & 0.34 \\
Model H & $0.718(0.651-0.786)$ & $71.8 \%$ & $69.5 \%$ & 0.413 & 2.35 & 0.41 \\
SII-PNI & $0.733(0.670-0.796)$ & $77.6 \%$ & $57.2 \%$ & 0.348 & 1.81 & 0.39 \\
CSS & & & & & & \\
Model I & $0.819(0.766-0.873)$ & $72.7 \%$ & $78.6 \%$ & 0.513 & 3.40 & 0.35 \\
Model J & $0.756(0.689-0.823)$ & $80.3 \%$ & $68.4 \%$ & 0.487 & 2.54 & 0.29 \\
SII-PNI & $0.720(0.652-0.789)$ & $54.5 \%$ & $79.6 \%$ & 0.341 & 2.67 & 0.57 \\
RFS & & & & & \\
Model K & $0.743(0.677-0.808)$ & $70.0 \%$ & $70.9 \%$ & 0.409 & 2.41 & 0.42 \\
Model L & $0.710(0.643-0.777)$ & $68.9 \%$ & $71.4 \%$ & 0.403 & 2.41 & 0.44 \\
SII-PNI & $0.645(0.574-0.716)$ & $45.6 \%$ & $79.7 \%$ & 0.253 & 2.25 & 0.68 \\
\hline
\end{tabular}

Figure 7. ROC analysis of the prognostic accuracy of SII-PNI for OS, CSS, and RFS in training cohort and validation cohort. 
Malnutrition can suppress immune system functions, increasing patient vulnerability to infection or cancer via cell-mediated mechanisms and other immune pathways [26, 27]. Malnutrition can also delay patients' surgery or adjuvant therapy. Thus, malnutrition is generally associated with unfavorable outcomes after surgery in many solid malignancies [9, 12]. However, few studies have investigated the association between nutritional status and systemic inflammation in patients with UTUC. PNI, a combination of serum albumin level and lymphocyte count, has been used to assess the nutritional status and has been identified as a risk factor for prognosis in UTUC patients. In the current study, serum PNI level was significantly negatively related to SII, NLR, PLR, and MLR. Thus, to some extent, we assume that a worse nutritional status in patients with cancer also indicates impairment of immune response and excessive infiltration of inflammatory components, leading to tumor development. The detailed mechanisms required further validation in the future studies.

Our results demonstrated that both SII and PNI were independent predictors of OS, CSS, and RFS in patients with UTUC. However, the predictive ability of the two biomarkers was relatively low with AUC of 0.647 (0.577-0.717) for SII and 0.596 (0.523-0.669) for PNI. The combination of SII and PNI had a better prognostic value over SII or PNI alone, with an AUC of 0.705 (0.639-0.772). The predictive value of SII-PNI was also validated in an independent cohort.

This study has several limitations. First, this was a retrospective study; thus, there may be selection bias during patient enrollment and data collection. However, another independent cohort was used to validate the results from the training cohort. Second, we did not assess other inflammatory scores, including C-reactive protein, IFN- $\gamma$ and TNF-a levels because of incomplete data. Third, the role of dynamic changes in SII-PNI on survival has not been evaluated because we lacked related data. Further studies should include this important information.

\section{Conclusions}

The findings of the current study suggest that the combination of SII and PNI may be a simple, noninvasive, easily accessible, and potentially effective indicator to evaluate the prognosis of patients of UTUC. Urologists should consider this novel biomarker for clinical decision-making and risk stratification.

\section{Abbreviations}

SII: systemic immune-inflammation index; PNI: prognostic nutritional index; UTUC: upper tract urothelial carcinoma; RNU: radical nephronureterectomy; OS: overall survival; CSS: cancerspecific survival; RFS: recurrence-free survival; AUC: area under the curve; NLR: neutrophil-to-lymphocyte ratio; PLR: platelet-to-lymphocyte ratio; MLR: monocyte-to-lymphocyte ratio; c-index: concordance index; IQR: interquartile range; ASA: American Society of Anesthesiologists; BMI: body mass index; CKD: chronic kidney disease; LVI: lymphovascular invasion; HR: hazard ratio; CI: confidence interval; IFN- $\gamma$ : interferon $-\gamma$; TNF-a: tumor necrosis factor-a.

\section{Supplementary Material}

Supplementary figures and tables. http://www.jcancer.org/v11p5665s1.pdf

\section{Acknowledgements}

The authors thank Editage for English language editing.

\section{Competing Interests}

The authors have declared that no competing interest exists.

\section{References}

1. Soria F, Shariat SF, Lerner SP, Fritsche HM, Rink M, Kassouf W, et al. Epidemiology, diagnosis, preoperative evaluation and prognostic assessment of upper-tract urothelial carcinoma (UTUC). World Journal of Urology. 2017; 35: 379-87.

2. Roupret M, Babjuk M, Comperat E, Zigeuner R, Sylvester RJ, Burger M, et al. European Association of Urology Guidelines on Upper Urinary Tract Urothelial Cell Carcinoma: 2015 Update. European Urology. 2015; 68: 868-79.

3. Fairey AS, Kassouf W, Estey E, Tanguay S, Rendon R, Bell D, et al. Comparison of oncological outcomes for open and laparoscopic radical nephroureterectomy: results from the Canadian Upper Tract Collaboration. BJU international. 2013; 112: 791-7.

4. Pichler M, Dalpiaz O, Ehrlich GC, Stojakovic T, Martin Hernandez JM, Mannweiler S, et al. Validation of the preoperative plasma fibrinogen level as a prognostic factor in a European cohort of patients with localized upper tract urothelial carcinoma. The Journal of Urology. 2014; 191: 920-5.

5. Kardoust Parizi M, Glybochko PV, Enikeev D, Roupret M, Fajkovic $H_{\text {, }}$ Seebacher V, et al. Risk stratification of upper tract urothelial carcinoma: A Review of the Current Literature. Expert review of anticancer therapy. 2019; 19: 503-13.

6. Jan $\mathrm{HC}$, Yang $\mathrm{WH}, \mathrm{Ou} \mathrm{CH}$. Combination of the Preoperative Systemic Immune-Inflammation Index and Monocyte-Lymphocyte Ratio as a Novel Prognostic Factor in Patients with Upper-Tract Urothelial Carcinoma. Annals of Surgical Oncology. 2019; 26: 669-84.

7. Vartolomei MD, Kimura S, Ferro M, Vartolomei L, Foerster B, Abufaraj M, et al. Is neutrophil-to-lymphocytes ratio a clinical relevant preoperative biomarker in upper tract urothelial carcinoma? A meta-analysis of 4385 patients. World Journal of Urology. 2018; 36: 1019-29.

8. Dalpiaz O, Krieger D, Ehrlich GC, Pohlmann K, Stojakovic T, Pummer K, et al. Validation of the Preoperative Platelet-to-Lymphocyte Ratio as a Prognostic Factor in a European Cohort of Patients with Upper Tract Urothelial Carcinoma. Urologia Internationalis. 2017; 98: 320-7.

9. Zhang $\mathrm{H}$, Shang X, Ren P, Gong L, Ahmed A, Ma Z, et al. The predictive value of a preoperative systemic immune-inflammation index and prognostic nutritional index in patients with esophageal squamous cell carcinoma. Journal of Cellular Physiology. 2019; 234: 1794-802.

10. Huang $\mathrm{X}, \mathrm{Hu} \mathrm{H}$, Zhang $\mathrm{W}$, Shao Z. Prognostic value of prognostic nutritional index and systemic immune-inflammation index in patients with osteosarcoma. Journal of Cellular Physiology. 2019; 234: 18408-14.

11. Tong YS, Tan J, Zhou XL, Song YQ, Song YJ. Systemic immune-inflammation index predicting chemoradiation resistance and poor outcome in patients with stage III non-small cell lung cancer. Journal of Translational Medicine. 2017; 15: 221.

12. Huang $J$, Yuan $Y$, Wang $Y$, Chen $Y$, Kong W, Xue W, et al. Preoperative prognostic nutritional index is a significant predictor of survival in patients with localized upper tract urothelial carcinoma after radical nephroureterectomy. Urologic Oncology. 2017; 35: 671.e1-.e9. 
13. Hanahan D, Weinberg RA. Hallmarks of cancer: the next generation. Cell. 2011; 144: 646-74.

14. Wang H, Zhao J, Zhang M, Han L, Wang M, Xingde L. The combination of plasma fibrinogen and neutrophil lymphocyte ratio (F-NLR) is a predictive factor in patients with resectable non small cell lung cancer. Journal of Cellular Physiology. 2018; 233: 4216-24.

15. Huang $\mathrm{H}$, Zhang $\mathrm{L}$, Chen $\mathrm{DB}$, $\mathrm{Yu} X \mathrm{XG}, \mathrm{He} \mathrm{XH}$, Liu $\mathrm{M}$, et al. Validation of Prognosis Value of Cumulative Prognostic Scores Based on Serum High-Density Lipoprotein Cholesterol and Albumin Levels in Patients with Colorectal Cancer. Journal of Cancer. 2019; 10: 35-42.

16. Hu X, Dou WC, Shao YX, Liu JB, Xiong SC, Yang WX, et al. The prognostic value of sarcopenia in patients with surgically treated urothelial carcinoma: A systematic review and meta-analysis. European journal of surgical oncology: the journal of the European Society of Surgical Oncology and the British Association of Surgical Oncology. 2019; 45: 747-54.

17. Mantovani A, Cassatella MA, Costantini C, Jaillon S. Neutrophils in the activation and regulation of innate and adaptive immunity. Nature reviews Immunology. 2011; 11: 519-31.

18. Muller I, Munder M, Kropf P, Hansch GM. Polymorphonuclear neutrophils and $\mathrm{T}$ lymphocytes: strange bedfellows or brothers in arms? Trends in Immunology. 2009; 30: 522-30.

19. Mantovani A, Allavena P, Sica A, Balkwill F. Cancer-related inflammation. Nature. 2008; 454: 436-44.

20. Moses K, Brandau S. Human neutrophils: Their role in cancer and relation to myeloid-derived suppressor cells. Seminars in Immunology. 2016; 28: 187-96.

21. Zhang K, Hua YQ, Wang D, Chen LY, Wu CJ, Chen Z, et al. Systemic immune-inflammation index predicts prognosis of patients with advanced pancreatic cancer. Journal of Translational Medicine. 2019; 17: 30.

22. Placke T, Kopp H-G, Salih HR. The Wolf in Sheep's Clothing: Platelet-derived "Pseudo Self" Impairs Cancer Cell "Missing Self" Recognition by NK Cells. Oncoimmunology. 2012; 1: 557-9.

23. Labelle M, Begum S, Hynes RO. Direct signaling between platelets and cancer cells induces an epithelial-mesenchymal-like transition and promotes metastasis. Cancer Cell. 2011; 20: 576-90.

24. Lavergne M, Janus-Bell E, Schaff M, Gachet C, Mangin PH. Platelet integrins in tumor metastasis: do they represent a therapeutic target. Cancers Basel. 2017; 9: $133-50$.

25. Oi $\mathrm{O}$, Zhuang $\mathrm{L}$, Shen $\mathrm{Y}$, Geng $\mathrm{Y}, \mathrm{Yu}$ S, Chen $\mathrm{H}$, et al. A novel systemic inflammation response index (SIRI) for predicting the survival of patients with pancreatic cancer after chemotherapy. Cancer. 2016; 122: 2158-67.

26. Marcos A, Nova E, Montero A. Changes in the immune system are conditioned by nutrition. European Journal of Clinical Nutrition. 2003; 57 Suppl 1: S66-9.

27. Chandra RK. Nutrition and the immune system: an introduction. The American Journal of Clinical Nutrition. 1997; 66: 460s-3s. 